IJASC 13-2-1

\title{
Exploiting Convergence of Life with Technology to Tackle Real-Life Problems by Means of Computer Games
}

\author{
Robert J. Wierzbicki, Peter Böhnke
}

University of Applied Sciences Mittweida, German

robert@wierzbicki.org, boehnke@hs-mittweida.de

\begin{abstract}
Convergence in technology and media makes it possible to augment nurturing by making blended infrastructures with new digital resources available in learning environments at schools. A game-based provision of educationally-valuable content within a collective, virtual environment combined with an analysis of events in the game after it has been played (blended nurture environment) may help to better communicate human values especially where old-fashioned discussion methods fail or do not fulfill the promise of effective, educational institution-based methods of bringing up. In this paper we discuss the use of behavioural metaphors in game-based blended-nurture scenarios for computer games and pedagogical-psychological tests. Upbringing demands an active intervention in the process of children growing up and the courage to place higher expectations on ourselves and our own lifestyles. Decisions and the behaviour of the younger generation are often irrational and the resulting effects can have destructive consequences. Nowadays, games take on the role of modern storytellers. With the help of complex analogies in games, a variety of situations can be depicted in an eye-catching way and later discussed.
\end{abstract}

Key words : behaviour, convergence, behavioural metaphor, behavioural habits, Blended Nurture, nurture games, pedagogics, cognition, upbringing, decision making, psychological levels, life, technology, evolution

\section{INTRODUCTION}

Discussing convergence these days it seems reasonable to shift the point of view towards life and technology convergence and talk about the merging of life sciences and digital experiences rather than consider convergence from a purely technological perspective. The ongoing blending of the real with the virtual in our lives as seen from an evolutionary perspective is an almost natural response to the technologization of life. In the past few years game design has become an important communication channel in the cross-media environment. Out of what was once purely an entertainment medium also a research topic has emerged; a topic not only of interest to educators, sociologists, psychologists, media experts, neuroscientists and marketing specialists.

Manuscript received: Sept. 10, 2013 / revised : Nov. 20, 2013

Corresponding Author: robert@wierzbicki.org

Tel: +49160844 9001, Fax: +4903727948146

University of Applied Sciences Mittweida, German
In the last few years the phenomenon of gamification has experienced a major boom. An ever-increasing number of tasks and processes in various parts of our lives - in private, at school, or at work - are formed by mechanisms from the world of games. In this way a new quality of emotion, acceptance, perception and mood develops. Shaped by social media and technological development, games are now a part of our contemporary digital culture. However, at the same time, in a world of electronic omnipresence and universal changeability, there is a growth in people's longing for socially-responsible integration in the real society, for true and genuine friendship and love, and for a retention of humanitarian values that people have worked hard for centuries to achieve. Through the continual virtualisation of social life, people lose the ability to approach other people in real life. On the Internet identities are disguised and distorted, feelings are faked, inhuman desires are satisfied, and the dark side of people's own existences is acted out. A continual defamiliarisation of the term "friendship" occurs and at the same time feelings of 
loneliness and isolation are developing more and more frequently in the real world

The blending of the real with the virtual in the lives of the younger generation is not generally to be perceived as a threat. Seen from an evolutionary perspective, it is an almost natural response to the technologisation of life. Humans rapidly adjust to a changing world. The problem is that upbringing and pedagogy do not seem to be following the increasingly faster process of the transformation of society into a digital society.

Considered within the framework of the nature-nurture problem, the dynamics of the evolutionary processes and their consequences is not examined in detail.

„In this quest, it is still early days, and it might still be asking too much of neuroscience to provide definitive answers to such contentious issues as the nature-nurture debate in brain development or the relative roles of genetics and environment in human behavior." [1]

\section{NURTURE GAMES}

\subsection{HUMAN BEHAVIOUR}

Human behaviour can be understood in different ways: as actions driven by nature, nurture and cultural background, as a motivated response to some emotional or environmental stimuli [2] or emerging out of a habit [3]. Within the framework of cognitivist theories human behaviour can be understood in terms of the mental processing of information [4]. Children observe the behaviour of adults and characters in the media, and often imitate what they have seen or heard in the hope that some of their behaviour will be positively received in certain circles or contexts. Where this is the case, behavioural habits can be formed, which in turn may result in bad behaviour. Duhigg explains habits on the basis of the cue-routine-reward loop. If the cues and rewards can be identified, the routine can be changed. In other words, a habit can be replaced even if it cannot be eradicated. When a habit emerges, the brain stops fully participating in rational decision making. According to Duhigg:

"Habits, scientists say, emerge because the brain is constantly looking for ways to save effort. Left to its own devices, the brain will try to make almost any routine into a habit, because habits allow our minds to ramp down more often." [3]

Bad behaviour in children is annoying. However, it does not necessarily have to be attributable to the imitation of bad behaviour or a bad upbringing. It can develop as a result of various different influences and become a habit. The child may not even realise that its behaviour is bad. The induced behaviour is not even aimed at annoying somebody. There can be a very simple explanation for throwing litter on the street - the fact that there are no rubbish bins. In Germany there is indeed a lack of rubbish bins in many streets, something the towns and local councils responsible for refuse collection justify on the grounds that often people would dispose of their household waste in them

\section{2. THE CONCEPT OF BLENDED NURTURE}

Upbringing requires an active intervention in the process of children growing up. Contemporary educational methods need adaptations which, like modern "blended learning" consist of a number of components. They need to combine moderated face-to-face methods with modern computer-mediated activities. The concept of blended nurture was introduced in an earlier paper by one of the authors [5]. The concept makes use of the idea of game-based provision of educationally-valuable content within a collective, virtual environment combined with an analysis of events in the game after it has been played. The authors of this paper are of the opinion that the positive, educational effects of providing content with the help of games cannot be brought about on their own. They can be effectively initiated with the help of a game, but they need the intervention of a moderator (coach) with whom the events of the game can be analysed and discussed within the group of players. The coach can, if necessary, qualify and correct the perception of game situations.

Nurture games should ideally be played in small groups. Game playing in small groups seems to be more effective in contrast with large-scale multiplayer game settings with a large number of players; the stories told can be kept more stringent in order to divert the attention of the players to particular aspects of the game. Also the collective actions and group dynamics can be better observed and evaluated, and it is easier to analyse decisions and their effects in the game. In small groups it is also much easier to avoid situations where a minority becomes the dominant group in the game - a probable situation according to the logic of collective action described theoretically by Olsen [6].

\section{3. BEHAVIOURAL METAPHORS}

Emotional storytelling serves as a basis for the design of nurture games. Stories are very particular bearers of meaning. They enable us to consider various aspects of the characters' lives, to feel sorry for them and to learn from them. Cognitive skills make it possible for us to remember the situation we have perceived - often with the same intensity as if it were reality. Generating emotions is a 
prerequisite for the effective communication of content which is portrayed or played out with the help of behavioural metaphors. What we call behavioural metaphors here are complex behavioural analogies in which the behaviour in the source domain is used to characterise behaviour in the target domain. In other words: a particular behaviour in a given situation can be mapped onto another situation and thus becomes a kind of prototype behaviour for a broad range of types of decision making. Behavioural metaphors structured in this way go further than the typical, visual-functional analogies. They are implemented in the form of metaphor-based interactions and are often embedded in untypical narrative situations.

We claim that metaphor-based game design can be an effective tool in understanding and correcting human behaviour in the process of upbringing, especially in pre-adolescence (age 8-13 years). Reasoning by analogy is generally considered to be a core component of human cognition [7]. Even children of pre-school age can already form complex analogies [8]. Young children's mental models determine analogical transfer across problems with a common goal structure. Pre-adolescent children undergo rapid cognitive development characterised by abstract thinking skills and advanced reasoning skills [9]. Especially the ability to think hypothetically and on multiple scales makes it possible to challenge their psyche through behavioural metaphors in game environments. We subscribe here to the theory of Bandura [10] who claims that complex human behaviour can be learned when people think about and evaluate the consequences of their behaviour. We also support a similar view of Skinner (Operant Conditioning Theory), who believed that the best way to understand behaviour is to look at the causes of an action and its consequences [11],[12]. According to Skinner, the consequences of responses serve to reinforce behaviour [13]. This is the point where videogames fit in because no other medium is able to showcase the consequences of actions so vivid and in an interactive way. As discussed above, with blended nurture we presuppose the presence of a coach. His or her functions are, among other things, the post-decision justification of decisions made and ensuring that the more complex metaphors in the game do not escape the intended perception. The great danger when employing metaphors is overburdening the recipient. In typical nurture games offered online, simple metaphors are used, which do not fulfil the purpose of in-depth nurture. We do not believe that in such a case any behavioural change can be initiated.

In the translation of various situations (source domain) to a game-based scenario, primarily two challenges must be developed for the player: make a decision (e.g. give in to or resist temptation) and bear the consequences of this decision, which cannot necessarily be foreseen in every case.
Game scenarios without real challenges very quickly lose their appeal.

A number of different situations can be conceived (target domain) which can be understood in the form of behavioural metaphors. One of the problems of our time is for example, (cyber-)harassment - the intimidation, oppression and coercion of other people using electronic means of communication over the Internet. Studies in Germany show that by now already around $1 / 3$ of adolescents and young adults are affected as victims of cyber-harassment. Approximately $1 / 5$ of those asked could imagine themselves as an offender on the Internet

"Previously young people argued in the school playground or mocked others in their cliques. Today they use the Internet or mobile phones to publish embarrassing photographs, post insults or to surf using a false identity." [14]

A far worse development can be observed in connection with radicalism, religious fanaticism, racist motivation, or sexual desires. The many cases of excessive use of violence, attacks by thugs and terrorist-motivated acts among young people, the victims of which often pay for with their lives, clearly demonstrate that young people are tending more and more to exceed moral boundaries. The offenders are becoming younger, more brutal and more inconsiderate. Again and again we ask the question how somebody can turn into a murder machine. Unfortunately there is no simple principle of causation for this with cause and effect. The fact is that the situation is too much for both parents and teachers. This makes it all the more important to discuss problems with upbringing and to look for new, appropriate contemporary ways to pass on value criteria as a fundamental component of upbringing.

\section{GAME-BASED PEDAGOGICAL AND PSYCHOLOGICAL DIAGNOSTICS}

Decision making is a cognitive process which requires an objective interpretation of information gathered. In children and adolescents these are often the current mood, emotion, level of fun or peer pressure which can significantly affect their cognitive biases [15]. "Fitting in" is important to most teens [16].

Decisions taken under such conditions are often irrational and they may have destructive effects. Regularly announcements can be heard on the radio warning of (young) people throwing stones from a bridge onto the motorway. The only explanation for such acts is that these people do not realise what consequences such actions can have. It is difficult to name any other motives which could 
lead someone to behave like that. From a psychological point of view, it is a pattern of cognitive ignorance which is not uncommon; a temporary blindness caused by focusing on a mostly short-term reward (fun, kick, fame or fortune); a situation, and thereby also a decision which leads to mistakes and causes harm. When modelling such situations for computer game-based scenarios and computer-supported, pedagogical and psychological diagnostics and therapy, we use a behavioural metaphor which we call the "Button, Button" metaphor - a situation we find in a short story "Button, Button" by Richard Matheson which first appeared in 1970 [17]. The story serves as a basis for the 20th episode of the first season (1985-1986) of the television series "The Twilight Zone" [18], and the movie "The Box" [19]. The characters in the story have to cope with the dilemma of pushing the button on a device delivered by a stranger which would bring them a lot of money at the expense of someone dying if they push the button. Someone whom they do not know. The story has a simple structure but deals with a serious, internal dilemma, brought about by a struggle when it comes to making a decision (psychological level 1): on the one hand the great temptation of making a lot of money relatively easily, and on the other hand the fear of doing something immoral, something which does not conform to human ethics. In both cases one is vulnerable to the consequences of one's decision (Table 1), which cannot always be foreseen. This makes up the second, most thrilling psychological level of the situation (Fig. 2) with extensive consequences of the action, which are often not foreseeable.

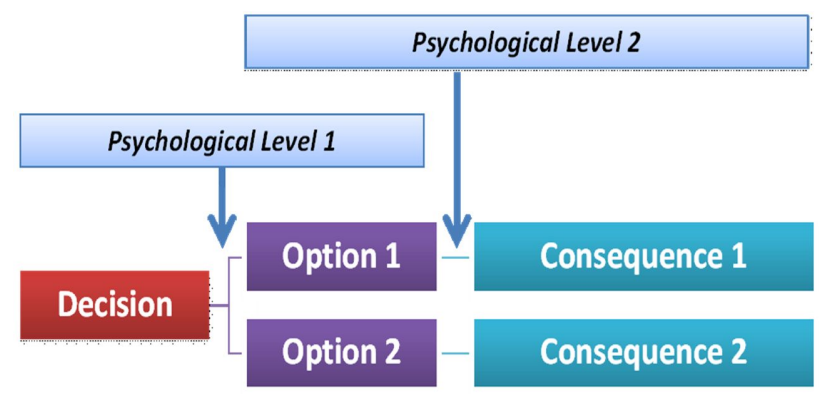

Figure 1. Psychological levels in decision making.

In Table 1. both the source and the target domain of the behavioural metaphor for two possible scenarios are shown.
Table 1. Examples of the mapping of the "Button, Button" metaphor onto another situations.

\begin{tabular}{|c|c|c|c|}
\hline \multicolumn{4}{|c|}{$\begin{array}{l}\text { Source domain (source of the behavioural metaphor): } \\
\text { "Button, Button" - metaphor }\end{array}$} \\
\hline \multicolumn{4}{|c|}{\begin{tabular}{l|l|l|l} 
Action & $\begin{array}{l}\text { Temptation } \\
\text { / Cause }\end{array}$ & $\begin{array}{l}\text { Primary } \\
\text { problem in } \\
\text { decision } \\
\text { making }\end{array}$ & $\begin{array}{l}\text { Possible } \\
\text { further, } \\
\text { non-foreseea } \\
\text { ble } \\
\text { consequence } \\
\text { s }\end{array}$ \\
& & & \\
& & & \\
\end{tabular}} \\
\hline \multicolumn{4}{|c|}{ 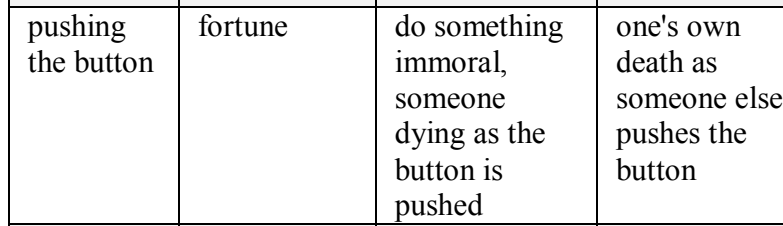 } \\
\hline Action & $\begin{array}{l}\text { Temptation } \\
\text { / Cause }\end{array}$ & $\begin{array}{l}\text { Primary } \\
\text { problem in } \\
\text { decision } \\
\text { making }\end{array}$ & $\begin{array}{l}\text { Possible } \\
\text { further, } \\
\text { non-foreseea } \\
\text { ble } \\
\text { consequence } \\
\text { s }\end{array}$ \\
\hline $\begin{array}{l}\text { throwing } \\
\text { stones } \\
\text { onto the } \\
\text { motorway }\end{array}$ & fun & damaging cars & $\begin{array}{l}\text { causing an } \\
\text { accident } \\
\text { resulting in } \\
\text { death, } \\
\text { custodial } \\
\text { sentence }\end{array}$ \\
\hline $\begin{array}{l}\text { harassmen } \\
\mathrm{t}\end{array}$ & $\begin{array}{l}\text { fun, } \\
\text { peer } \\
\text { pressure }\end{array}$ & $\begin{array}{l}\text { intimidation } \\
\text { or oppression } \\
\text { of a person }\end{array}$ & $\begin{array}{l}\text { death } \\
\text { (suicide) of } \\
\text { the harassed } \\
\text { person, } \\
\text { be oneself a } \\
\text { victim of } \\
\text { harassment }\end{array}$ \\
\hline
\end{tabular}

\section{SUMMARY}

Convergence has changed the way we think about education and especially about nurture. But we mistakenly believe that digitally supported education and computer-mediated communication will solve the problems which have accumulated within societies over time.

The main purpose of this paper was to emphasise the role of behavioural metaphors in game-based scenarios for nurture games with a primary focus on pedagogical and psychological diagnostics and the modelling of behaviour. 'Metaphors', in particular behavioural metaphors, is a topic dealt with relatively marginally in education studies.

The authors are of the opinion that it is urgently necessary to adopt a position in the process of upbringing using correct patterns - values and norms - and to adopt new methods of communicating them in pedagogy, especially through games. This is important so as to build real social and life skills in children and adolescents and to better prepare them to predict the effects of their behaviour and decisions. The overall goal is to alleviate the effects of 
ego threats at the conscious and unconscious level.

Decisions in life may be irreversible, and their consequences can be very serious, leading to psychological tension and trauma. Young people often perform actions led by temporary fun and spontaneous, emotional attitudes, or which emerge out of peer-pressure. These actions often lack any rationality and they may have tragic consequences the youngsters are not aware of.

We claim that metaphor-based game design can be an effective tool in understanding and correcting human behaviour, especially in blended-nurture environments. Looking at the causes of an action, evaluating its consequences and mapping the outcomes to other situations seems to be a powerful means of nurturing and fostering personal responsibility and respect for others.

At the University of Applied Sciences in Mittweida, Germany, a series of psychological tests utilizing behavioural metaphors are currently (2013) under development. The tests provide the basis for more complicated scenarios in multiple player games. The problem is that the design of nurture games requires cooperation between the media sector, psychologists and game designers, and it is not always easy to bring all of these together. This is where the convergence of life and technology is extremely valuable and desired.

Game publishers are skeptic when it comes to bringing a game onto the market which has more psychological depth [20]. In today's world everything is geared towards generating income and games with an educational focus just don't sell well, if at all. For this reason more commitment is needed by educational institutions and ministries. It is only then that we will be in a position to preserve human values in society.

\section{ACKNOWLEDGMENT}

This paper was completed within the framework of the project PrävEm [25] supported by The European Social Fund (ESF) and the Saxon Ministry of Science and the Fine Arts (SMWK) in 2013.

\section{REFERENCES}

[1] Dowling, J. E.: The great brain debate: nature or nurture? Joseph Henry Press (2004)

[2] Baer, J., Kaufman, J.s C. \& Baumeister, R. F. (Eds.): Are we free?: psychology and free will. Oxford University Press (2008)

[3] Duhigg, C.: The Power of Habit. Random House Inc., New York (2012)

[4] Coon, D.: Psychology: A Modular Approach to Mind and Behavior, 10. Edition. Thomson Learning (2006).
[5] Wierzbicki, R. J.: Blended Nurture in T.-h. Kim et al. (Eds.): ASEA/DRBC/EL 2011, CCIS 257, pp. 643-650, 2011. Springer-Verlag Berlin Heidelberg (2011)

[6] Olson, M. The Logic of Collective Action: Public Goods and the Theory of Groups. Cambridge, MA: Harvard University Press (1965)

[7] Goswami, U.: Analogical Reasoning in Children. Hillsdale, NJ: Lawrence Erlbaum Associates (1992)

[8] Brown, A. L., Kane, M. J., \& Echols, C. H.: Young children's mental models determine analogical transfer across problems with a common goal structure. Cognitive Development, 1, 103-121 (1986)

[9] Steinberg, L.: Adolescence (8th Edition). New York: McGraw-Hill (2007)

[10] Bandura, A.: Social Cognitive Theory of Mass Communication, in Media Psychology, 3, 265-299. Lawrence Erlbaum Associates (2001)

[11] Skinner, B.F.: The Behavior of Organisms: An Experimental Analysis. Cambridge, MA: B.F. Skinner Foundation (1938/1999)

[12] McLeod, S. A.: B.F. Skinner | Operant Conditioning (2007).

Retrieved

from http://www.simplypsychology.org/operant-conditioning. html (June 4, 2011)

[13] Reynolds, G.S.: A primer of operant conditioning. Glenview, IL: Scott, Foresman, and Company (1968)

[14] TK-Studie Cybermobbing - Gewalt unter Jugendlichen. Repräsentative Forsa-Umfrage für NRW und das Bundesgebiet www.tk.de/centaurus/servlet/contentblob/360188/Datei/6 3714/Forsa-Umfrage\%20Cybermobbing\%20Bund.pdf (June 4, 2011)

[15] Schwarz, N., Bless, H. and Bohner, G.: Mood and persuasion: affective states influence the processing of persuasive communications. Advances in Experimental, Social Psychology, 24, 161-99 (1991)

[16] Wilson, J., Krapp, Kristine M.: The Gale Encyclopedia of Children's Health (2nd edition), Cengage Gale (2011)

[17] Matheson R.: Button, Button: Uncanny Stories. Tor Books (2008)

[18] imdb.com, http://www.imdb.com/title/tt0052520/ (June 4, 2011)

[19] imdb.com, http://www.imdb.com/title/tt0362478/ (June 4, 2011)

[20] Miller, H. C.: Digital Storytelling: A Creator's Guide to Interactive Entertainment. Butterworth Heinemann, p. 220 (2008)

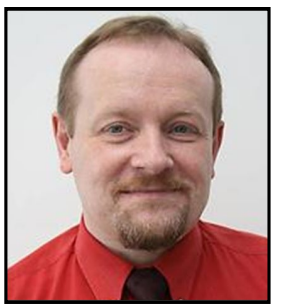

Prof. Dr.-Ing. Robert J. Wierzbicki (b. 1959)

1984: Technical University Wroclaw, Poland (Dipl.-Ing. Univ.)

1993: Fraunhofer Institute for Integrated Circuits / 
Technical University Erlangen-Nürnberg

(Doctor of Engineering Sciences, Dr.-Ing.)

Current: University of Applied Sciences Mittweida, Germany (Professor for Online Media)

\section{Principal Scholarly Interests :}

interactive media, creative content design, game psychology, media effects of computer games on children and adolescents, neurosciences, nurture-based games

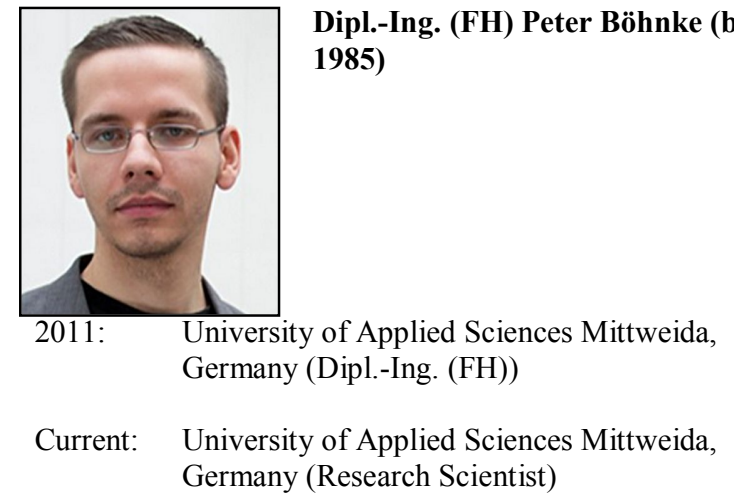

Principal Scholarly Interests :

game psychology, cognitive distortion, gamification, modelling of human behaviour in virtual environments 